\title{
Pelatihan Bahasa Inggris Berequivalent TOEFL Pada Reading Test CBT Terhadap Mahasiswa Semester Akhir Di Universitas Muhammadiyah dan IAIN Palangka Raya
}

\author{
Equivalent English TOEFL Training in CBT Reading Tests for Final Semester Students at \\ Muhammadiyah University and IAIN Palangka Raya
}

A'am Rifaldi Khunaifi*
Ilham
Bayu Suratmoko
Department of Elementary Teacher
Education, Universitas
Muhammadiyah Palangkaraya,
Palangka Raya, Central Kalimantan,
Indonesia

*email: aamrifaldi@gmail.com
Kata Kunci
Pelatihan
Membaca Komprehensif
TOEFL
CBT
Keywords:
Training
Reading Comprehension
TOEFL
CBT
Accepted: February 2020

\begin{abstract}
Abstrak
Bahasa Inggris merupakan bahasa Internasional. Di Indonesia, bahasa Inggris diajarkan sebagai bahasa asing (English as a Foreign Languange/EFL) mulai dari Sekolah Dasar sampai Perguruan Tinggi (Huda, 1999, dalam Saukah, 2003). Khususnya di Universitas Muhammadiyah Palangkaraya dan IAIN Palangka Raya menganggap penting bahasa Inggris yang ditunjukkan melalui tes TOEFL dan memenuhi skor yang ditentukan sebelum mereka Yudisium atau Munakasah dan telah menyelesaikan sidang skripsi dalam satu semester. Peserta kegiatan ini berjumlah 20 peserta yang berasal dari Mahasiswa UM Palangkaraya dan IAIN Palangkaraya. Metode pelatihan yang digunakan dalam pelatihan Bahasa Inggris berequivalent Toefl pada Reading Tes adalah dengan menggunakan modul pelatihan Toefl pada Reading Tes dan juga menggunakan Program software secara komputerisasi dalam pelatihan Toefl pada Reading Tes. Hasil pelatihan ini Kegiatan pelatihan ini menunjukan adanya peningkatan antara hasil pre test dan post test. Rerata pre test adalah 61 dan rerata post test meningkat menjadi 83.6. Pada pretes yang dilakukan kepada 20 peserta berada pada kategori rendah dengan jumlah 4 orang, ketagori sedang 13 orang dan tinggi 3 orang. Hasil post test menunjukan peningkatan skor yaitu kategori rendah 4 orang, kategori sedang 12 orang dan kategori tinggi meningkat menjadi 4 orang.
\end{abstract}

\begin{abstract}
English is an international language. In Indonesia, English is taught as a foreign language (English as a Foreign Language/EFL) from Elementary Schools to Higher Education. Especially at the University of Muhammadiyah Palangkaraya and IAIN Palangka Raya consider the importance of English which is shown through the TOEFL test and meet the scores determined before they are Judisium or Munakasah and have completed the thesis hearing in one semester. There were 20 participants from the Palangkaraya UM Students and Palangkaraya IAIN. The training method used in the English equivalent of Toefl training on Reading Tests is to use the Toefl training module on Reading Tests and also using a computerized software program in Toefl training on Reading Tests. The results of this training The training activities showed an increase between the pre-test and post-test results. The mean pre-test was 61 and the posttest mean increased to 83.6. In the pretest conducted to 20 participants were in the low category with a total of 4 people, a medium category of 13 people and a high of 3 people. The post-test results showed an increase in the score, namely the low category of 4 people, the medium category of 12 people and the high category increased to 4 people.
\end{abstract}




\section{PENDAHULUAN}

Bahasa Inggris diajarkan dalam bentuk "General English" atau "Language Form" (bentuk bahasa), pembentukan kata, ejaan, ucapan, dan sebagainya diintegrasikan ke dalam keempat keterampilan berbahasa, yaitu menyimak, berbicara, membaca dan menulis (Angyuningsih, 2013). Para siswa harus menguasai empat keterampilan bahasa tersebut sehingga mereka dapat menggunakan bahasa Inggris aktif dan pasif juga (Kurniawati, 2015). Writing (menulis) sebagai bagian dari keterampilan bahasa selain menyimak, berbicara, dan membaca, harus diajarkan secara maksimal oleh guru kepada siswa (Arono, 2013).

Khususnya di Universitas Muhammadiyah Palangkaraya dan IAIN Palangka Raya menganggap penting bahasa Inggris yang ditunjukkan melalui tes TOEFL dan memenuhi skor yang ditentukan sebelum mereka Yudisium atau Munakasah dan telah menyelesaikan sidang skripsi dalam satu semester. Tes TOEFL ini bertujuan agar setiap mahasiswanya dapat menjadi seorang sarjana yang berkualitas, yaitu mampu untuk mengungkapkan ide secara lisan maupun tulisan dalam bahasa Inggris. Dengan demikian mereka akan mudah mencari pekerjaan di tengah-tengah persaingan dalam bidang pekerjaan sekarang ini. Selain itu tes TOEFL ini juga dapat mempermudah mahasiswa yang ingin melanjutkan sekolah ke luar Negeri (Suniati et al., 2017).

Membaca bahwa metodologi untuk menjadi lebih berkenalan dengan beberapa kata-kata dan mengkoordinasikan ke pentingnya kata-kata menjadi kalimat dan struktur meneliti (Aprinawati, 2018). Dengan cara ini, di bangun dari meneliti dapat membuat esensi dari bagian. Dapat diambil kesimpulan bahwa Reading adalah prosedur pemahaman dan mengambil pentingnya kata, berpikir, pikiran, gagasan, dan data yang telah dikemukakan oleh penulis dalam menyusun
(Muis, 2013). Seketika membaca mengingat fakta bahwa dengan membaca dengan teliti, ilmu pengetahuan, Anda akan mengembangkan. Bahan untuk membaca dengan teliti itu berbagai sumber meneliti, bisa menjadi bacaan saja, majalah, koran harian, dan hutan yang berbeda (Setyawati, 2011).

TOEFL merupakan singkatan dari Test Of English as a Foreign Language. TOEFL adalah standardisasi kemampuan bahasa inggris seseorang secara tertulis yang meliputi beberapa aspek penguasaan: Listening, Writing dan Reading.

TOEFL memiliki dua tujuan umum yaitu: Academic dan General. Tujuan akademik TOEFL adalah untuk tujuan pendidikan, penelitian atau yang berhubungan dengan kegiatan akademis di luar negeri, ataupun di Indonesia. Untuk paska sarjana, biasanya nilai minimal adalah 550 sedangkan untuk S1 adalah 500. Tujuan umum (general) pada umumnya digunakan dalam bidang pekerjaan, kenaikan pangkat atau tugas kerja. Banyak perusahaan yang memasang standar bahasa inggris karyawannya dengan melihat nilai TOEFL. Umumnya, nilai TOEFL minimal adalah 500 untuk kenaikan pangkat standar (Siregar, 2016).

Mahasiswa di Universitas Muhamamdiyah Palangkaraya dan IAIN Palangka Raya sebagai Perguruan Tinggi yang mencetak sarjana-sarjana yang profesional, mengemban tiga fungsi utama dalam pendidikan yaitu mengembangkan potensi kecerdasan, penanaman nilai-nilai, dan pengembangan kemampuan/skill dasar, termasuk di dalamnya kemampuan bahasa Inggris. Yang termasuk pengembangan kemampuan dasar adalah menulis English sentence. Oleh karena itu sangat dipandang perlu mengembangkan metode pengajaran, terutama pengajaran bahasa Inggris yang menyenangkan dengan tujuan memberikan pembelajaran tanpa memberi beban (Yamin, 2017). Semua ini sejalan dengan pola yang 
dianut pada pendidikan yang modern yaitu belajar menyenangkan.

Dalam upaya peningkatan kualitas sumber daya manusia di dunia pendidikan, penguasaan bahasa asing, tertama bahasa Inggris, merupakan suatu hal yang sangat penting. Hal ini didasari atas berbagai pertimbangan. Dengan memberlakukan standar mutu internasional, sebuah sekolah telah berkomitmen untuk memasuki sebuah ranah pengelolaan yang tidak lagi berpatokan pada standar dan tuntutan mutu lokal sehingga memerlukan sumber daya manusia yang mampu memahami seluk beluk informasi yang yang dibutuhkan dalam ranah sehingga dapat mendukung kinerja mereka dalam mewujudkan komitmen lembaga. Penyampaian materi secara dwi-bahasa merupakan tuntutan wajib bagi sekolah-sekolah bertaraf internasional. Hal ini tentu saja mustahil dilaksanakan jika para guru/pengajar tidak memiliki kompetensi berbahasa Inggris. Oleh karena itu, upaya untuk meningkatkan penguasaan bahasa Inggris bagi guru dan karyawan merupakan bukti keseriusan (Syafii \& Sugianto, 2017).

\section{METODOLOGI}

Alat atau bahan yang digunakan dalam pelaksanaan pengabdian adalah sebagai berikut:

1. Pelatihan Keterampilan Reading Comprehesion

Pelatihan Bahasa Inggris berequivalent TOEFL pada Reading Test adalah dengan menggunakan modul pelatihan TOEFL pada Reading Test dan juga menggunakan Program software secara komputerisasi dalam pelatihan TOEFL pada Reading Test.

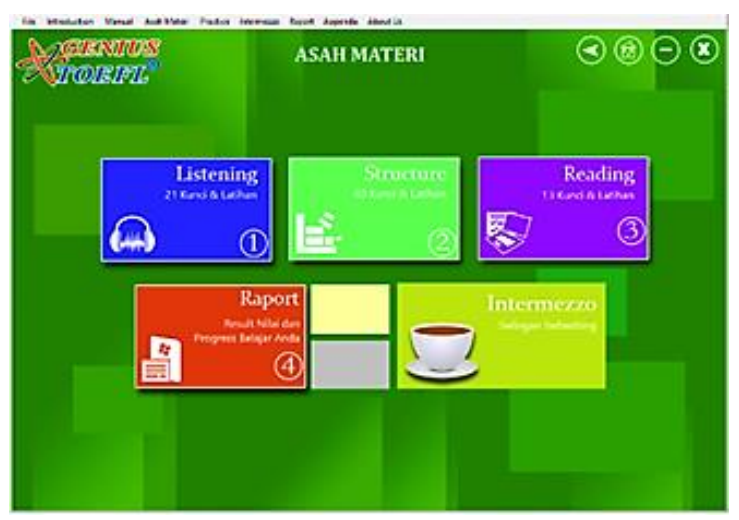

Gambar 1. Modul Program Tes TOEFL

2. Lembar Soal

Lembar Soal dibuat berdasarkan pada materi pelatihan keterampilan Reading Test dengan quiz secara online

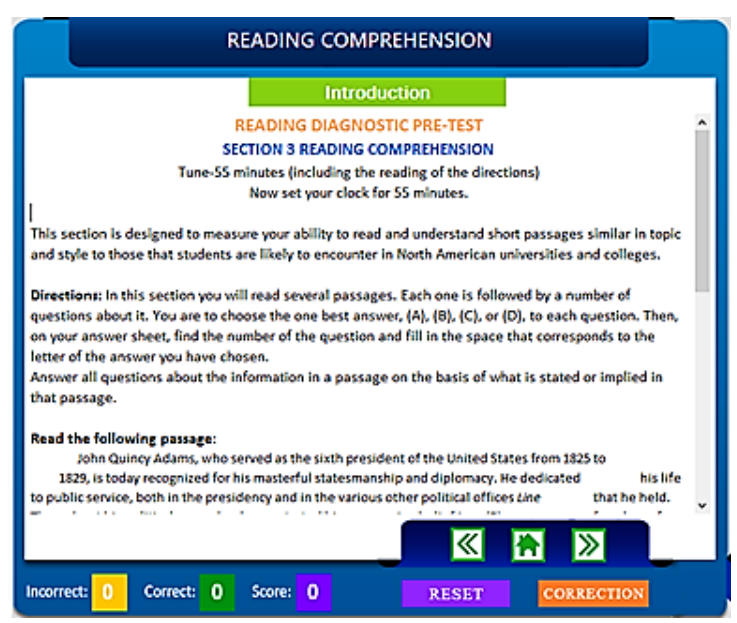

Gambar 2. Lembar soal

3. Modul Pelatihan TOEFL

Materi modul pelatihan ini berisi bahan yang berkaitan dengan keterampilan Reading Comprehension mengambil pentingnya kata, berpikir, pikiran, gagasan, dan data yang telah dikemukakan oleh penulis dalam menyusun. Seketika membaca mengingat fakta bahwa dengan membaca dengan teliti, ilmu pengetahuan, Anda akan mengembangkan.

Kegiatan pelatihan ini dilakukan selama lima hari, dimulai pada hari Senin, 15 Juli 2019 dan berakhir pada hari Jumat 19 Juli 2019. 


\section{Hari Pertama}

Pada hari pertama ini peserta kan diberikan duan materi berupa pengetahuan mengenai Tes TOEFL dan Skill Of Language. Setiap materi selesai dilaksanakan diskusi kelompok selanjutnya pada akhir kegiatan diberikan evaluasi untuk mengetahui kemampuan peserta pada hari tersebut dan diberikan tugas rumah agar peserta tetap berlatih.

2. Hari Kedua

Pada hari pertama ini peserta kan diberikan materi berupa Pengenalan jenis-jenis TOEFL, Reading Comprehension dan Praktek Secara Komputerisasi dan Skill Of Language. Setiap materi selesai dilaksanakan diskusi kelompok selanjutnya pada akhir kegiatan diberikan evaluasi untuk mengetahui kemampuan peserta pada hari tersebut dan diberikan tugas rumah agar peserta tetap berlatih.

\section{Hari Ketiga}

Pada hari pertama ini peserta kan diberikan materi berupa Skill OfReading dan Praktek dengan Software. Setiap materi selesai dilaksanakan diskusi kelompok selanjutnya pada akhir kegiatan diberikan evaluasi untuk mengetahui kemampuan peserta pada hari tersebut dan diberikan tugas rumah agar peserta tetap berlatih.

4. Hari Keempat

Pada hari pertama ini peserta kan diberikan materi berupa . Keterampilan Scaning dan Keterampilan Skimming. Setiap materi selesai dilaksanakan diskusi kelompok selanjutnya pada akhir kegiatan diberikan evaluasi untuk mengetahui kemampuan peserta pada hari tersebut dan diberikan tugas rumah agar peserta tetap berlatih.

\section{Hari Kelima}

Pada hari pertama ini peserta kan diberikan duan materi berupa Reading Test dan Computer Based Test
Setiap materi selesai dilaksanakan diskusi kelompok selanjutnya pada akhir kegiatan diberikan evaluasi untuk mengetahui kemampuan peserta pada hari tersebut dan diberikan tugas rumah agar peserta tetap berlatih.

\section{HASIL DAN PEMBAHASAN}

Hasil dari pelaksanaan pengabdian ini, akan dijabarkan dibawah ini sesuai dengan langkah-langkah atau metode pelaksanaan kegiatan pengabdian yang dilakukan. Setiap akhir sesi dilakukan evaluasi untuk mengetahui kemajuan peserta pada setiap sesi.

1. Pretest

Tujuan Pretest ini adalah untuk mengetahui kemampuan awal peserta sebelum diberikan pelatihan. Adapun hasil dari pretest dapat dilihat pada tabel di bawah ini:

Tabel I. Skor awal pre test

\begin{tabular}{|c|c|c|c|}
\hline No & Subjek & Nilai & Kategori \\
\hline 1 & A & 56 & Sedang \\
\hline 2 & B & 64 & Sedang \\
\hline 3 & C & 50 & Rendah \\
\hline 4 & $\mathrm{D}$ & 63 & Sedang \\
\hline 5 & E & 67 & Sedang \\
\hline 6 & $\mathrm{~F}$ & 70 & Tinggi \\
\hline 7 & G & 54 & Rendah \\
\hline 8 & $\mathrm{H}$ & 55 & Sedang \\
\hline 9 & I & 61 & Sedang \\
\hline 10 & $\mathrm{~J}$ & 66 & Sedang \\
\hline 11 & K & 68 & Tinggi \\
\hline 12 & L & 63 & Sedang \\
\hline 13 & M & 60 & Sedang \\
\hline 14 & $\mathrm{~N}$ & 58 & Sedang \\
\hline 15 & $\mathrm{O}$ & 72 & Tinggi \\
\hline 16 & P & 54 & Rendah \\
\hline 17 & $\mathrm{R}$ & 53 & Rendah \\
\hline 18 & S & 65 & Sedang \\
\hline 19 & $\mathrm{~T}$ & 57 & Sedang \\
\hline 20 & $\mathrm{U}$ & 64 & Sedang \\
\hline
\end{tabular}


Tabel II. Rerata dan SD pre test

\begin{tabular}{clcc}
\hline No & Skor Rata-rata & Kategori & Jumlah \\
\hline 1 & $X \geq 67.2$ & Tinggi & 3 \\
2 & $54.8 \leq X<67.2$ & Sedang & 13 \\
3 & $X<54.8$ & Rendah & 4 \\
\hline Total & & 20 \\
\hline Mean $\mathbf{= 6 1} ;$ SD $=\mathbf{6 . 2}$ & & \\
\hline
\end{tabular}

Berdasarkan tabel diatas dapat dilihat bahwa rerata skor pretes adalah 61. Berdasarkan kategori, 3 peserta dengan kategori Tinggi, 13 peserta dengan kategori sedang dan 4 peserta dengan kategori rendah.

\section{Post test}

Setelah kegiatan yang diaksanakan selama 5 hari. Pada ahri terakhir diadakan kegiatan post test, tujuanya untuk mengetahui apakah kegiatan paltihan ini dapat meningkatkan skor kemampuan memahami bacaan pada peserta. Adapun hasil dari post test dapat dilihat pada tabel di bawah ini:

Tabel III. Skor Post test

\begin{tabular}{cccc}
\hline No & Subjek & Nilai & Kategori \\
\hline 1 & A & 80 & Sedang \\
2 & B & 78 & Rendah \\
3 & C & 85 & Sedang \\
4 & D & 85 & Sedang \\
5 & E & 90 & Tinggi \\
6 & F & 84 & Sedang \\
7 & G & 75 & Rendah \\
8 & H & 75 & Rendah \\
9 & I & 88 & Sedang \\
10 & J & 95 & Tinggi \\
11 & K & 85 & Sedang \\
12 & L & 83 & Sedang \\
13 & M & 85 & Sedang \\
14 & N & 80 & Sedang \\
15 & O & 90 & Tinggi \\
16 & P & 75 & Rendah \\
17 & R & 80 & Sedang \\
18 & S & 85 & Sedang \\
19 & T & 83 & Sedang \\
20 & U & 90 & Tinggi \\
\hline
\end{tabular}

Tabel IV. Rerata dan SD post test

\begin{tabular}{clcc}
\hline No & Skor Rata-rata & Kategori & Jumlah \\
\hline 1 & $X \geq 89.1$ & Tinggi & 4 \\
2 & $78.1 \leq X<89.1$ & Sedang & 12 \\
3 & $X<78.1$ & Rendah & 4 \\
\hline Total & & & 20 \\
\hline Mean $=\mathbf{8 3 . 6} ;$ SD $=\mathbf{5 . 5}$ & & \\
\hline
\end{tabular}

Berdasarkan tabel diatas dapat dilihat bahwa rerata skor postes adalah 83.6. Berdasarkan kategori, 4 peserta dengan kategori Tinggi, 12 peserta dengan kategori sedang dan 4 peserta dengan kategori rendah.

Pada pengabdian ini, metode pelatihan yang digunakan dalam pelatihan Bahasa Inggris berequivalent TOEFL pada Reading Test adalah dengan menggunakan modul pelatihan TOEFL pada Reading Test dan juga menggunakan Program software secara komputerisasi dalam pelatihan TOEFL pada Reading Test.

Bahasa Inggris berekuivalensi TOEFL merupakan salah satu aspek dalam pelatihan bahasa Inggris yang menekankan pada peningkatan penguasaan skil dasar seperti Structure, Reading, dan Listening. Masing-masing bidang memiliki metode pembelajaran dan oprientasi yang berbeda. Structure menekankan pada pemahaman hal-hal yang berhubungan dengan tata bahasa seperti jenis-jenis kata, tipe-tipe kalimat, frasa, hubungan antar elemen kalimat, tenses, dan sebagainya. Pengetahuan tentang struktur bahasa sangat dibutuhkan tidak hanya bagi pembelajar bahasa Inggris untuk tujuan akademik, namun juga bagi mereka yang mempelajari bahasa Inggris untuk tujuan yang lebih praktis. Hal ini antara lain karena struktur/grammar bersifat spesifik dan sering berbeda antara satu bahasa dengan bahasa lain (Syafii \& Sugianto, 2017).

Bahasa Inggris memiliki struktur/grammar yang sangat berbeda dengan bahasa Indonesia. Perbedaan tata bahasa ini juga tentu saja berpengaruh pada bentukbentuk ujaran, baik lisan maupun tertulis. Oleh karena itu, pengetahuan struktur ini akan berpengaruh pada 
kemampuan lain seperti listening, reading, dan speaking (Kurniawati, 2015).

Dalam reading (terutama Reading comprehension) orientasi utamanya adalah pemahaman teks (bacaan). Hal yang paling mendasar dalam memahami sebuah teks berbahasa asing adalah penguasaan kosa kata. Dengan penguasaan kosa kata yang kaya, seorang pembaca akan lebih mudah memahami isi atau pesan yang terkandung dalam sebuah teks. Dalam reading kosa kata dapat dibedakan menjadi dua, kosa kata umum dan kosa kata khusus atau teknis. Kosa kata umum adalah kata-kata yang secara umum digunakan dalam berbagai tingkat komunikas dan tidak secara khusus terkait dengan topik tertentu. Sedangkan kosa kata khusus atau teknis adalah kata-kata atau istilah-istilah yang secara eksklusif terkait dengan topik-topik atau bidang tertentu (Santosa, 2017). Hal lain yang sangat dalam reading adalah pemahaman tentang topik bacaan dan pesan yang ingin disampaikan oleh penulis. Kedua hal ini membutuhkan telaah bacaan yang lebih mendalam dan latihan yang cukup memadai dan beragam karena tiap-tipa teks biasanya memiliki topik dan pesan yang berbeda dan spesifik.

\section{KESIMPULAN}

Kegiatan pelatihan ini menunjukan adanya peningkatan antara hasil pre test dan post test. Rerata pre test adalah 61 dan rerata post test meningkat menjadi 83.6. Pada pretes yang dilakukan kepada 20 peserta berada pada kategori rendah dengan jumlah 4 orang, ketagori sedang 13 orang dan tinggi 3 orang. Hasil post test menunjukan peningkatan skor yaitu kategori rendah 4 orang, kategori sedang 12 orang dan kategori tinggi meningkat menjadi 4 orang.

\section{UCAPAN TERIMA KASIH}

Ucapan terima kasih serta penghargaan sebesarbesarnya tim pelaksana pengabdian yang berjudul
“Pelatihan Bahasa Inggris Berequivalent TOEFL Pada Reading Test CBT Terhadap Mahasiswa Semester Akhir di Universitas Muhammadiyah dan IAIN Palangka Raya" kepada Lembaga Penelitian dan Pengabdian kepada Masyarakat yang telah mendanai kegaitan ini melalui Hibah Pengabdian Kepada Masyarakat dengan skema PKMS, Kepala Laboratorium bahasa, Teknisi laboratorium serta instruktur pelatihan serta seluruh mahasiswa dari UM Palangkaraya dan IAIN Palangkaraya terutama 20 mahasiswa yang menjadi peserta selama kegiatan pelaksanaan berlangsung, serta seluruh tim pelaksana pengabdian yang telah banyak membantu untuk mensukseskan kegiatan pengabdian ini.

\section{REFERENSI}

Angyuningsih, N.W.E. 2013. Peningkatan Kemampuan Keterampilan Berbicara Siswa Kelas IV SD Dalam Pembelajaran Introduction. Linguistika: Buletin Ilmiah Program Magister Linguistik Universitas Udayana. 20(3):1-17.

Aprinawati, I. 2018. Penggunaan Model Peta Pikiran (Mind Mapping) Untuk Meningkatkan Pemahaman Membaca Wacana Siswa Sekolah Dasar. Jurnal Basicedu. 2(1):140-147.

Arono, A. 2013. Pengembangan Pembelajaran Keterampilan Menyimak Melalui Teknologi Informasi. Jurnal Pendidikan Bahasa dan Sastra. 13(2):129-148.

https://doi.org/10.17509/bs_jpbsp.v13i2.286

Kurniawati, D. 2015. Studi Tentang Faktor-Faktor Penyebab Kesulitan Belajar Menyimak Bahasa Inggris Pada Mahasiswa Semester III PBI IAIN Raden Intan Lampung Tahun Pelajaran 2015/2016. English Education: Jurnal Tadris Bahasa Inggris. 8(1):1-22. https://doi.org/10.24042/ee-jtbi.v8i1.515

Muis, S.F. 2013. Kemampuan Membaca Pemahaman Literal Dan Interpretatif Melalui Pendekatan Konstruktivisme. Al-Munzir. 6(2):272-285. http://dx.doi.org/10.31332/am.v6i2.263 
Santosa, P.P.P. 2017. Pengaruh Penguasaan Kosakata terhadap Kemampuan Membaca Teks Persuasif Bahasa Inggris Siswa Kelas X SMK Negeri 2 Depok. Deiksis. 9(2):170-181. http://dx.doi.org/10.30998/deiksis.v9i02.182 3

Setyawati, C.K. 2011. Pengembangan Pembelajaran Keterampilan Membaca Melalui Penerapan Teknik Tari Bambu. Jurnal llmiah Guru "COPE". 17-23.

Siregar, M.N.G. 2016. Aplikasi Media Pembelajaran Mandiri Tes TOEFL Menggunakan Metode Fuzzy Berbasis Android. Skripsi. Malang: Universitas Islam Negeri Maulana Malik Ibrahim.

Suniati, S., Khunaifi, A.R., Setyawan, D. 2017. Pelatihan Bahasa Inggris Berekuivalen TOEFL terhadap Mahasiswa Universitas Muhammadiyah Palangkaraya. PengabdianMu: Jurnal Ilmiah Pengabdian kepada Masyarakat. 2(1):47-52. https://doi.org/10.33084/pengabdianmu.v2i 1.119

Syafii, L., Sugianto, A. 2017. Pelatihan Bahasa Inggris Berekuivalensi TOEFL Bagi Dosen Universitas Muhammadiyah Ponorogo. Adimas: Jurnal Pengabdian Kepada Masyarakat. 1(1):25-30. http://dx.doi.org/10.24269/adi.v1i1.414

Yamin, M. 2017. Metode Pembelajaran Bahasa Inggris Di Tingkat Dasar. Pesona Dasar (Jurnal Pendidikan Dasar dan Humaniora). 1(5):82-97. 